\title{
Some Growth Characteristics of Tetrahymena sp., a Parasite of Guppy, Poecilia reticulata and the Effect of a Mixture of Two Commonly used Protozoacides on its Population Density
}

\author{
D.C. HETTIARACHCHI ${ }^{1}$ AND M. HETTIARACHCHI ${ }^{2}$ \\ ${ }^{1}$ Confifi Aquaculture Ventures (Pvt) Ltd \\ No. 33, St. Michael's Street, Colombo 3, Sri Lanka \\ ${ }^{2}$ Department of Zcology, \\ University of Kelaniya, Kelaniya \\ Sri Lanka \\ * Corresponding Author (E-mail: dchris@slnet.lk)
}

\begin{abstract}
Various species and strains of Tetrahymena have a potential for being more virulent especially when the water is high in organic matter and fish are immunologically depressed causing "Tetrahymenosis". An outbreak of Tetrahymenosis was experienced by Sri Lankan guppy farmers in the recent past for which different treatments were employed indiscriminately. Present study investigated some growth characteristics of this fish parasite, which could be useful in import risk analysis and in screening female brooders of guppy. Tetrahymena sp. tested multiply rapidly in the presence of freshly killed guppy (as the substrate) and chloramphenicol $50 \mu \mathrm{g} \mathrm{ml}^{-1}$ with a generation time of 2.6 hours at $28^{\circ} \mathrm{C}$. Combined effect of methylene blue $\left(2 \mathrm{mg} \mathrm{l}^{-1}\right)$ and Zinc free malachite green $\left(0.03 \mathrm{mg} \mathrm{l}^{-1}\right)$ completely inhibited in situ multiplication of Tetrahymena.
\end{abstract}

\section{Introduction}

Poecilia reticulata, commonly known as guppy is a popular tropical omamental fish of which different varieties account for a greater proportion of the total freshwater ornamental fish export from Sri Lanka. In the recent past, guppy farms in Sri Lanka experienced an outbreak of a disease known as "guppy disease", "Tet disease", "Tetrahymenosis", or "guppy killer disease", which caused high mortalities resulting in significant economic losses (Hettiarachehi and Hettiarachchi 1999; Hettiarachchi and Amaratunga 2000). Southgate (1993) and Gratzek 
(1993) described the causative agent of "Tet disease" as a Tetrahymena species, a normal free living, freshwater, polysaprobic, opportunistic, ciliate parasite. Gratzek (1993) and Butcher (1993) reported that various species and strains of Tetrahymena have a potential for being more virulent especially when the water is high in organic matter and fish are immunologically depressed. According to Lin et al. (1993) T. pyriformis is a free-living, non-pathogenic ciliated protozoan that occasionally becomes parasitic on live-bearing fish. $T$. corlissi is more pathogenic and guppies and other live bearers are the most susceptible species to this parasite. Infestation of $T$. corlissi produces signs of necrosis and hemorrhagic areas on the skin of fish and foci of parasites have been found in kidneys, brain and muscles (Butcher 1993). Laoprasert et al. (2002) also reported on "Tetrahymenosis" in guppy while Wakita et al. (2002) reported on Tetrahymenosis in dwarf gourami indicating that the parasite could be a threat to even egg layers.

During the outbreak, many Sri Lankan guppy farmers treated the infected guppies with different chemicals and broad-spectrum antibiotics such as chloramphenicol indiscriminately. However, farmers themselves have observed that severity of the disease increased with the use of antibiotics indicating that there exist an interaction between Tetrahymena and bo "uid. Literature on growth characteristics of Tetrahymena sp. are scarce and therefore this work was undertaken to study some growth characteristics of this parasite and to develop methods to amplify population density (for quarantine purposes) and to control it which could be useful in the health management of guppy populations.

\section{Materials and Methods}

\section{Stock culture of Tetrahymena sp.}

Ten dead Poecilia reticulata which were heavily infected with Tetrahymena sp. were collected from a commercial guppy farm and stored in $200 \mathrm{ml}$ of water at $4-6^{\circ} \mathrm{C}$ as the stock culture. This stock culture was vigorously shaken before taking inocula. Wet mounts prepared from skin lesions of infested guppy were observed under the microscope and the parasite was identified to generic level according to Jahn (1970).

\section{Growth characteristics of Tetrahymena sp.}

\section{Effect of different culture conditions on population density}

Freshly killed uninfected Poecilia reticulata measuring about 1.5 $\mathrm{cm}$ in total length (TL) were used as the substrate for Tetrahymena sp. Five different culture conditions (A, B, C and D) and a control (E) were 
arranged in triplicate as shown in Table 1 and were inoculated with $100 \mu \mathrm{i}$ of stock culture of Tetrahymena sp.

Table 1. The different culture conditions provided for Tetrahymena sp. E is the control culture condition.

\begin{tabular}{|c|c|c|c|c|c|}
\hline \multirow[t]{2}{*}{ Treatment } & \multicolumn{5}{|c|}{ Culture condition } \\
\hline & A & B & C & $\mathrm{D}$ & E \\
\hline $\begin{array}{l}\text { Culture volume (ml) } \\
\text { (aged tap water) }\end{array}$ & 10 & 10 & 10 & 10 & 10 \\
\hline $\begin{array}{l}\text { Freshly killed one guppy as } \\
\text { substrate }(1.5 \mathrm{~cm} \text { in } \mathrm{TL})\end{array}$ & + & + & - & 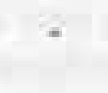 & . \\
\hline $\begin{array}{l}\text { Freshly killed and autoclaved } \\
121^{\circ} \mathrm{C} \text { one guppy as substrate } \\
(1.5 \mathrm{~cm} \text { in TL) }\end{array}$ & - & - & - & + & - \\
\hline $\begin{array}{l}\text { Freshly killed and macerated one } \\
\text { guppy as substrate }(1.5 \mathrm{~cm} \text { in } \\
\text { TL) }\end{array}$ & - & - & + & a & - \\
\hline Incubating temperature ${ }^{\circ} \mathrm{C}$ & $28 \pm 1$ & $4 \pm 1$ & $28 \pm 1$ & $28 \pm 1$ & $28 \pm 1$ \\
\hline Tetrahymena inoculurn & + & + & + & + & + \\
\hline
\end{tabular}

After shaking the culture vigorously, eight samples of $50-100 \mu 1$ (for counting convenience) were taken from each vial with a variable micropipette (1-1000 $\mu \mathrm{l}$ Pipetteman) at 24 hour intervals for 72 hours and the number of organisms were counted under the light microscope using one drop of $2 \%$ formalin to kill the organisms.

\section{Effect of chloramphenicol on the population density of Tetrahymena sp.}

Twelve Tetrahymena cultures were arranged providing the conditions that supported the maximum population density and four different concentrations of chloramphenicol each with 3 replicates (25, 50, 100 and $200 \mu \mathrm{g} / \mathrm{ml}$ ) were added to these cultures separately. This was done to find out the best antibiotic concentration that inhibits competing bacterial populations in the culture. The cultures were then inoculated with an equal number of Tetrahymena sp. Eight samples of $25-100 \mu l$ from each culture (depending on the age of the culture) were taken at 24 hour intervals after shaking the culture vigorously and the Tetrahymena was enumerated as in the previous experiment. The generation time was calculated for the exponential phase of the culture which had the highest growth rate using $t / n$, where $t$ is the time in hours and $n$ is the number of generations during 
the exponential growth phase which was obtained from the equation $\mathbf{n}=$ $\log \mathrm{N}-\log \mathrm{N}_{0} / \log 2$ where $\mathrm{N}$ is final cell number, and $\mathrm{N}_{0}$ is initial cell number (Madigan et al. 1997).

\section{Growth curve of clones of Tetrahymena sp.}

Three vials, each containing aged tap water with $50 \mu \mathrm{g} \mathrm{ml}^{-1}$ chloramphenicol (the concentration which gave the maximum population density of Tetrahymena sp.) and freshly killed P. reticulata were inoculated separately with one cell of Tetrahymena sp. using micromanupulation. Eight samples of culture medium $(25-100 \mu \mathrm{l}$, depending on the age of the culture) were withdrawn from each vial at 24 hour intervals for 15 days and the Tetrahymena population was enumerated. A growth curve was plotted using the mean number of Tetrahymena sp. recorded at each sampling interval.

Effect of a mixture of two commonly used protozodcides on the population density of Tetrahymena sp.

Composition of the culture medium arranged to investigate the effect of two protozoacides commonly used in ornamental fish culture, namely methylene blue and zinc free malachite green oxalate is given in Table 2; the concentrnticas of the two protozoacides were chosen after series of preliminary tests. Here, three replicates were arranged with the protozoacides and the control (without protozoacides), which also had three replicates. Eight $100 \mu \mathrm{l}$ samples were withdrawn from each replicate at 24 hour intervals for seven days and the presence or absence of Tetrahemena sp. in the samples were observed under the microscope.

Table 2. Composition of the culture medium arranged to investigate the effect of protozoacides on population density of Tetrahymena sp.

\begin{tabular}{ll}
\hline Component & Amount/Concentration \\
\hline Aged tap water & $10 \mathrm{ml}$ \\
Chloramphenicol $\left(50 \mu \mathrm{g} \mathrm{ml}^{-1}\right)$ & $500 \mu \mathrm{g}$ \\
Substrate & one dead guppy $(1.5 \mathrm{~cm} \mathrm{TL})$ \\
Inoculum (stock culture) & $100 \mu \mathrm{l}$ \\
Zinc free malachite green oxalate & $0.0003 \mathrm{mg}$ \\
$\left(0.03 \mathrm{mg} \mathrm{l}^{-1}\right)$ & \\
Methylene blue (2.00 $\left.\mathrm{mg} \mathrm{l}^{-1}\right)$ & $0.02 \mathrm{mg}$ \\
\hline
\end{tabular}


Growth characteristics of Tetrahymena.

\section{Results}

Two rows of cilia, which began at the mouth (oral groove) and extended posteriorly, were observed on Tetrahymena sp. under the light microscope. A long single cilium was also observed among the cilia at the posterior end of the organism.

Infected guppies showed white patches just in front of the dorsal fin and haemorrhagic lesions on the caudal penduncle. Freshly killed whole guppy at ambient temperature $\left(28 \pm 1^{\circ} \mathrm{C}\right.$; Treatment A) gave significantly higher population density of Tetrahymena sp. than in other treatments $(\mathrm{P}<$ 0.05 ) throughout the 72 hour period while the lowest population density was recorded in the culture containing macerated substrate (Treatment $\mathrm{C}$, Figure 1).

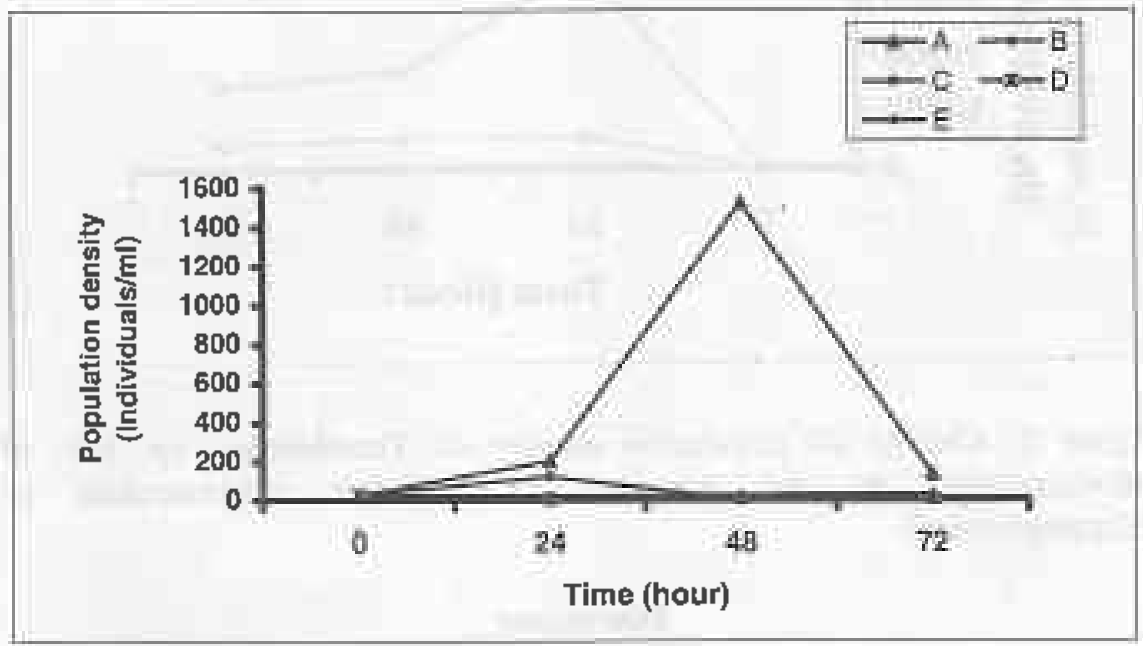

Figure 1. Change of the population density of Tetrahymena sp. with time under different culture conditions (for A, B, C, D, and E, refer Table 1).

Chloramphenicol at the concentration of $50 \mu \mathrm{g} \mathrm{m} \mathrm{m}^{-1}$ supported the highest population density of Tetrahymena sp. $(\mathrm{P}<0.01)$ when combined with the best culture conditions (freshly killed whole guppy as the substrate at ambient temperature). The maximum density $(36,000$ individuals $/ \mathrm{ml})$ was achieved 24 hours after inoculation and the generation time of the population during the exponential phase was 2.6 hours. Chloramphenicol at $\left.200 \mu \mathrm{g} \mathrm{m}\right|^{-1}$ completely inhibited the growth of the population of Tetrahymena sp. while $25 \mu \mathrm{g} \mathrm{m}{ }^{-1}$ chloramphenicol had supported a considerable increase in the number of Tetrahymena sp. (Figure 2). Figure 3 shows the growth curve of clones of Tetrahymena sp. observed during the 
15 day culture period. The maximum density of the parasite in clones was reached 11 days after inoculation.

Tetrahymena sp. was absent in all the samples taken from the cultures containing the mixture of chemicals, zinc free malachite green oxalate (0.03 $\mathrm{mg} \mathrm{l}^{-1}$ ) and methylene blue ( $2.0 \mathrm{mg} \mathrm{l}^{-1}$ ), while it was present in the samples taken from the cultures without the chemicals.

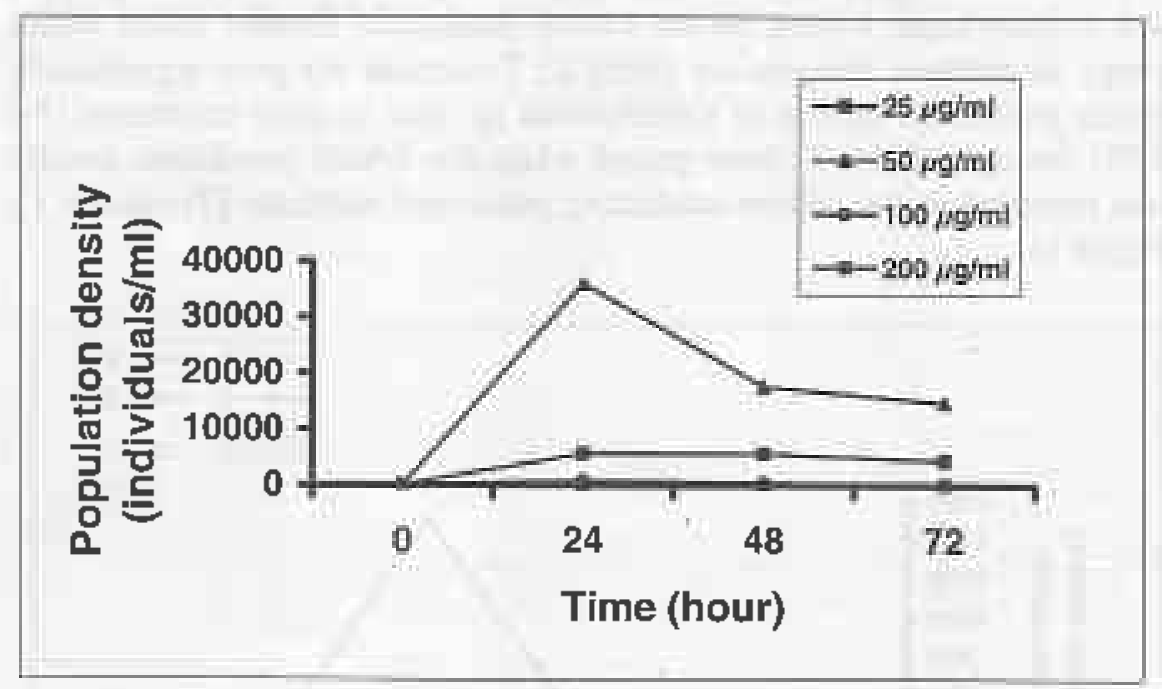

Figure 2. Change of population density of Tetrahymena sp. (no. of individuals $/ \mathrm{ml}$ ) in the presence of different concentration of chloramphenicol:

\section{Discussion}

Presence of two rows of cilia, which begin at the oral groove and extended posteriorly confirmed that the ciliate in the present study belongs to the genus Tetrahymena (Jahn 1970). Results of the present study suggest that freshly killed unprocessed tissues of Poecilia reticulata support a good growth of Tetrahymena sp. in situ at ambient temperature of $28 \pm 1^{\circ} \mathrm{C}$. According to Lin et al. (1993), T.pyriformis could be cultured aerobically in an enriched medium. Significantly higher population density of Tetrahymena sp. $(\mathrm{P}<0.01)$ ) that resulted in the culture medium containing $50 \mu \mathrm{g} \mathrm{ml}{ }^{-1}$ of chloramphenicol suggests that the antibiotic has suppressed the competing bacterial populations in the medium allowing the ciliate to multiply rapidly. It has also been reported that the use of novobiocin (an antibiotic) had increased the number of individuals of Tetrahymena sp. causing increased mortality in infected guppies (Ponpornpisit et al. 1998). 
Growth characteristics of Tetrahymend.

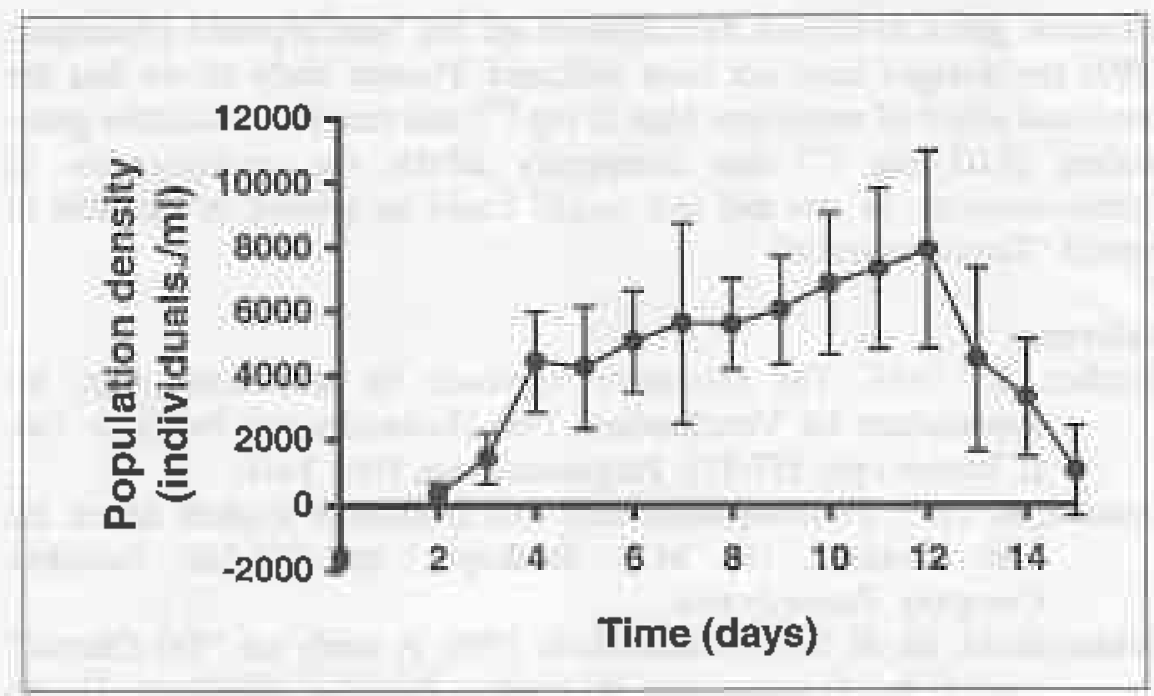

Figure 3. Growth curve of Tetrahymena sp. Vertical bars are \pm S.E.

Short generation time $(2.6 \mathrm{~h})$ recorded in the present study revealed that the parasite could multiply in the culture tanks in the presence of dead guppies during a very short period of time. In order to test whether guppy stocks imported are contaminated with this parasite, it could be allowed to multiply in a medium with the best culture conditions found out during the present study. This would be very useful in import risk analysis and even in screening brood stocks transported within the country in order to prevent the spread of the disease. Commonly recommended doses of chloramphenicol given via water for bacterial diseases of frsh ranged from $20-50 \mu \mathrm{g} \mathrm{ml}^{-1}$ (Untergasser 1989; Scott 1993). Significantly lower (P<0.01) population density of Tetrahymena sp. recorded in the cultures containing $25 \mu \mathrm{g} \mathrm{ml}^{-1}$ of chloramphenicol suggests that this dosage was not sufficient to inhibit the competing bacterial populations and the maximum inhibition of bacteria occurs at a dose of $50 \mu \mathrm{g} \mathrm{ml}^{-1}$ of the antibiotic. It was observed that chloramphenicol at higher concentrations ( $100 \mu \mathrm{g} \mathrm{ml}^{-1}$ and $200 \mu \mathrm{g} \mathrm{ml}^{-1}$ ) inhibited the Tetrahymena population also due to unknown reasons; however, the use of chloramphenicol in aquaculture is totally banned.

The growth curve of clones (Figure 3) obtained shows that Tetrahymena sp. could utilize nutrients from dead tissues of guppy over an extended period of time and this is an important fact that should be considered in the control of the spread of this disease.

During the recent outbreak of "Tetrahymenosis ", many Sri Lankan guppy farmers used the Leteux Mayer mixture (Scott 1993) without a success, which is a combination of malachite green and formalin, recommended for external protozoan infections. Although the use of 
malachite green to control Tetrahymena sp. has been reported (Southgate 1993) the dosages have not been indicated. Present study shows that the combined effect of methylene blue $\left(2 \mathrm{mg}^{-1}\right)$ and zinc free malachite green oxalate $\left(0.03 \mathrm{mg} \mathrm{l}^{-1}\right.$ ) can completely inhibit the multiplication of Tetrahymena sp. in situ and this results could be applied in the field to control "Tetrahymenosis".

\section{Reference}

Butcher, R. 1993. The veterinary approach to ornamental fish. In: Aquaculture for Veterinarians, Fish Husbandry and medicine. (ed. L. Brown ) pp. 357-377. Pergamon Press, New York.

Gratzek, R. 1993. Parasites associated with freshwater tropical fishes. In: Fish Medicine, (ed. MK. Stoskopf) pp. 573-560. Saunders Company, Pennsylvania.

Hettiarachchi, M. \& D.C. Hettiarachchi 1999. A study on "Tet Disease" caused by Tetrahymena in guppy, Poecilia reticulata. Fourth Symposium on Diseases in Asian Aquaculture, Cebu city, Philippines, Nov. 22-26 p 68.

Hettiarachchi, M. \& K.S.K.H. Amaratunga 2000. A study on the disease caused by Tetrahymena sp. (a ciliate protozoan) in guppy, Poecilia reticulata. Proceedings of the $56^{\text {th }}$ Annual Sessions of the Sri Lanka Association for the Advancement of Science. p. 173.

Jahil, T.L. 1970. How to know the protozoa. In: The Protozoa p. 194-195. Brown and Company Publishers, Iowa.

Laoprasert, T., S. Chinabut \& K. Hatai 2002. Study on Tetrahymena infection in guppy (Poecilia reticulata). Fifth Symposium on Diseases in Asian Aquaculture, Gold Coast, Australia Nov. 24-28, p. 121.

Lin, K.H., Y.M. Sin, \& J.T. Lam, 1993. Protection of goldfish against some common ectoparasitic protozoans using Ichthyopthirius multifiliis and Tetrahymena pyriformis for vaccination. Aquaculture 166: 303314.

Madigan, M.T., J.M. Martinko and J. Parker 1997. Biology of Microorganisms. Prentice Hall, New Jersey.

Ponpornpisit, A., M. Endo \& H. Murata 1998. The study of guppy fish infected with a protozoa Tetrahymena. Proceedings of the Fifth Asian Fisheries Forum, Thailand. p. 177.

Scott, P. 1993. Therapy in aquaculture. In: Aquaculture for Veterianarians, Fish Husbandry and Medicine. (ed. L. Brown ) pp. 131-152, Pergamon Press, New York.

Southgate, P. 1993. Diseases in aquaculture. In: Aquaculture for veterinarian, Fish Husbandry and Medicine. (ed. L. Brown ) pp. 91129. Pergamon Press, New York. 
Growth characteristics of Tetrahymena.

Untergasser, D. 1989. Hand book of fish diseases. TFH Publishers, Neptune, New Iersey.

Wakita. K, L Soichi, \& K. Hatai 2002, Histopathological study on Tetrahymena infection in dwarf gourami (Colisa lafia). Fitth Symposium on Diseases in Asian Aquaculture, Gold Cosst, Australia Nov. 24-28, p 134. 